\title{
Fourier Dönüşümlü Kızılötesi Spektroskobi ile Kızartma Yağlarındaki Bazı Kimyasal Değişimlerin İncelenmesi
}

\author{
Ayşe Burcu Aktaş ${ }^{1 *}$, Melda Melihat Erdal ${ }^{2}$, Dilber Kaya ${ }^{3}$, Fatma Aycan Yiğit ${ }^{4}$ \\ 1* Sivas Cumhuriyet Üniversitesi, Fen Fakültesi, Biyokimya Bölümü, Sivas, Türkiye, (ORCID: 0000-0003-2520-0976), burcuaktas@cumhuriyet.edu.tr \\ ${ }^{2}$ Sivas Cumhuriyet Üniversitesi, Mühendislik Fakültesi, Gıda Mühendisliği Bölümü, Sivas, Türkiye (ORCID: 0000-0001-6863-5617), erdalmelda42@gmail.com \\ ${ }^{3}$ Sivas Cumhuriyet Üniversitesi, Mühendislik Fakültesi, Gida Mühendisliği Bölümü, Sivas, Türkiye (ORCID: 0000-0003-1605-2481), dilberrkayaa@outlook.com \\ ${ }^{4}$ Sivas Cumhuriyet Üniversitesi, Mühendislik Fakültesi, Gida Mühendisliği Bölümü, Sivas, Türkiye (ORCID: 0000-0003-0575-3194), fatmaaycanyigit@gmail.com
}

(Uluslararası Araştırma-Geliştirme ve Tasarım Konferansı - 15-18 Aralık 2021)

(DOI: $10.31590 /$ ejosat.1040464)

ATIF/REFERENCE: Aktaş, A. B., Erdal, M. M., Kaya, D. \& Aycan Yiğit, F. (2021). Fourier Dönüşümlü Kızılötesi Spektroskobi ile Kızartma Yağlarındaki Bazı Kimyasal Değişimlerin İncelenmesi. Avrupa Bilim ve Teknoloji Dergisi, (32), $542-547$.

\section{$\ddot{O} \mathbf{z}$}

Bu çalışmada derin yağda kızartma işlemi sırasında kanola ve bitkisel susuz yağda meydana gelen kimyasal değişikliklerin belirlenmesi amaçlanmıştır. Donmuş parmak patateslerin kızartılması için yağ tipi ve kızartma tekrarı faktör olarak düşünülerek bir faktöriyel deneme deseni oluşturulmuştur. Bu deneme desenine göre toplam 11 farklı kızartma işlemi gerçekleştirilmiştir. Dondurulmuş patates örnekleri, belirtilen yağlar ile, ev tipi elektrikli bir fritözde 4 dakika boyunca, $180^{\circ} \mathrm{C}$ 'de taze yağ eklenmeksizin kızartılmıştır. Bütün yağ örnekleri için serbest yağ asitliği, peroksit sayısı, konjuge dien ve trien $\left(\mathrm{K}_{232}\right.$ ve $\left.\mathrm{K}_{270}\right)$ değerleri belirlenmiştir. Ayrıca, Fourier dönüşümlü kızılötesi spektrometre ile spektralar toplanarak, kızartma yağlarında meydana gelen kimyasal değişimlerin daha iyi analiz edilmesi ve örneklerin sınıflandırılması sağlanmıştır. Elde edilen veriler varyans analizi (ANOVA) ve çok değişkenli (PCA) istatiksel yöntemlerle açıklanmıştır. ANOVA sonuçları, yağ tipi ve kızartma tekrarının yağların peroksit sayısı ve konjuge dien ve trien değerleri üzerine önemli bir etkisi olduğunu göstermektedir. Temel bileşenler analizi (PCA) ile kızartma işleminde kullanılan yağ örneklerinin yağ tipini göre sınıflandırılması sağlanmıştır (3 BS, $\left.\mathrm{R}^{2}=0,97\right)$. Elde edilen verilere göre $180{ }^{\circ} \mathrm{C}$ 'de gerçekleştirilecek derin yağda kızartma işleminde kanola yă̆ı kullanılması ve taze eklemeksizin kızartma işleminin en fazla 7 kez tekrarlanması önerilir.

Anahtar Kelimeler: derin yağda kızartma, kızıl ötesi spektra, kızartma yağları.

\section{Determination of Some Chemical Changes in Frying Oils by Fourier Transform Infrared Spectrum}

\begin{abstract}
The purpose of this study is to determine some chemical changes occurring in canola oil and anhydrous fat during deep frying process. For frying frozen potato samples, a factorial design was constructed by considering the oil type and the number of frying as factors. 11 different frying processes were carried out according to the experimental design. Frozen potato samples were fried in a domestic deepfat electrical fryer for 4 minutes at $180^{\circ} \mathrm{C}$ without oil replenishment. Free fatty acid content, peroxide value and $\mathrm{K}_{232}, \mathrm{~K}_{270}$ values were determined for all oil samples. Moreover, collection of Fourier-transform infrared (FTIR) spectra during frying process is also aimed in order to better characterize and classify frying oil samples. The data were analyzed by analysis of variance (ANOVA) and principal component analysis (PCA). ANOVA results showed that, oil type and number of frying have significant effects on peroxide number and conjugated diene and triene values of the samples. The PCA model with $3 \mathrm{PCs}, \mathrm{R}^{2}=0.97$ revealed that there is a separation of the frying oil samples with respect to oil type. According to the data obtained, it is recommended to use canola oil in deep oil frying for maximum 7 times at $180{ }^{\circ} \mathrm{C}$.
\end{abstract}

Keywords: deep frying, infrared spectra, frying oils.

\footnotetext{
*Sorumlu Yazar: burcuaktas@cumhuriyet.edu.tr
} 


\section{Giriş}

Gıdaların pişirilmesi amacıyla yaygın olarak kullanılan yöntemlerden birisi kızartma işlemidir. Derin yağda kızartma, gıda maddesinin tamamının veya tamamına yakın bir kısmının yağa batırılarak pişirildiği bir işlemdir (Moreira, 2014; Sebastian vd., 2014). Bu işlemde, 1s1 ve kütle transferi birlikte gerçekleşir. Isı yağdan gıdaya transfer olurken, gıdanın içerdiği su buharlaşarak yağ tarafından adsorplanır (Bou vd., 2012; Rababah vd., 2012). Kızartma işlemi sırasında sıcaklık, nem ve oksijen etkisi ile, oksidasyon, polimerizasyon ve hidroliz reaksiyonları başlar ve kızartma yağında farklı bozunma ürünleri oluşur (Sunisa vd., 2011; Warner, 2002). Kızartma işlemi sırasında sıcaklığın ve oksijenin etkisi ile başlayan serbest radikal oluşumu ve sonrasında ilerleyen zincirleme reaksiyonlar sonucunda aldehitler, ketonlar, hidrokarbonlar, laktonlar, alkoller, asitler gibi çok çeşitli oksidasyon ürünleri oluşur (Tzusuki vd., 2010; Yemişçioğlu vd., 2015). Buna ek olarak, polimerizasyon reaksiyonları sonucunda da birçok dimerik, oligomerik asitlerin ve gliseridlerin miktarı $\operatorname{artar}$ (Ahmad vd., 2021). Ayrıca, trigliseridlerin hidrolizasyonu ile serbest yağ asitleri ve gliseridler oluşur. Oluşan bu bileşiklerin sağlık açısından zararlı oldukları ve özellikle kansere sebebiyet verdikleri daha önceki çalışmalarda açıklanmıştır (Fujisaki vd., 2002; Saguy ve Dana, 2003).

Derin yağda kızartma işleminde kullanılacak yağların rafine edilmiş, dumanlama noktası yüksek, laurik asit gibi orta zincirli yağ asitlerini ve çoklu doymamış yağ asitlerini içermeyen özelliklerde olması gerekmektedir. Bu nedenle, kızartma işlemi için özel olarak üretilmiş yüksek oleik asitli ve düşük oranda çoklu doymamış yağ asitleri içeren yağlar tercih edilebilir. Ayrıca kullanılacak yağların serbest yağ asitliği ve polar madde içeriği de düşük olmalıdır (Weisshaar, 2014). Derin yağda kızartma işleminde dikkat edilmesi gereken bir diğer parametre, taze yăg eklemeksizin aynı yağ ile kaç kez kızartma işleminin terkrarlanabileceğidir. $\mathrm{Bu}$ nedenle, gıdalara kızartma işlemi uygulanırken, belirli aralıklarla kızarmış yağ örnekleri alınarak kimyasal değişimlerin gözlenmesi gerekmektedir. Ayrıca, derin yağda kızartma işlemi sırasında gerçekleşen hidrolizasyon reaksiyonları, bitkisel susuz yağların kullanımıyla azaltılabilir.

$\mathrm{Bu}$ araştırmanın amacı, derin yağda kızartma işleminde kullanılan kanola ve bitkisel susuz yağlarının kızartma prosesi boyunca uğradığı kimyasal değişimlerin incelenmesidir. Donmuş patatesler bir faktöriyel deneme deseni kurularak kızartılmış ve kızartma işleminin belirli tekrarlarında yă örnekleri alınarak, gerçekleşen kimyasal değişimler hem analitik yöntemlerle hem de kızılötesi spektrumla belirlenmiştir. Ayrıca, kızartma ortamına taze yağ eklemeksizin kaç kez kızartma işlemi gerçekleştirilebileceği de tespit edilmiştir.

\section{Materyal ve Metot}

\subsection{Derin Yağda Kızartma İşlemi}

Bu çalışmada donmuş patatesler, ev tipi elektrikli bir fritözde derin yağda kızartılmıştır (Tefal, Fransa). Donmuş patatesler (Superfresh, Türkiye), rafine kanola yağ 1 (Aysan, Türkiye) ve bitkisel susuz yağ (Vita, Türkiye) süpermarketten satın alınmıştır. Donmuş patateslerin kızartılması için yağ tipi (bitkisel susuz yağ ve kanola yağı) ve kızartma tekrarı (3-5-7-12) faktör olarak düşünülerek bir Faktöriyel Deneme Deseni oluşturulmuştur (Tablo 1). Bu deneme desenine göre 11 farklı kızartma işlemi yapılmıştır. Başlangıçta fritöze yaklaşık $2000 \mathrm{ml}$ yağ konularak ve her defasında 100 gr donmuş patates kızartılmıştır. Kızartma işlemi $180^{\circ} \mathrm{C}$ 'de 4 dakika boyunca gerçekleştirilmiştir. Kızartma işlemi taze yă̆ eklenmeksizin tekrarlanıp, 3, 5 ve 7 ve 12 . tekrarlarda kızartma yağlarından örnekler alınarak bazı kimyasal analizler yapılmıştır. Tüm kimyasal analizler iki tekrarlı gerçekleştirilmiştir.

\subsection{Kimyasal Analizler}

\subsection{1. \%Serbest Yă̆ Asitliği (SYA);}

Kızartılmış yağ örneklerinin serbest yağ asitliği yüzdesi AOCS Official Method Ca 5a-40'a göre yapılmıştır. Örneklerin serbest yağ asitliği \% oleik asit cinsinden hesaplanmıştır.

\subsubsection{Peroksit Sayısı Tayini (PS);}

Kızartma yağ örneklerinin peroksit değerleri AOCS Official Method Cd 8-53 ile belirlenmiştir. Örneklerin peroksit değeri sonuçları $1 \mathrm{~kg}$ yağda bulunan peroksit oksijenin mili eşdeğer oksijen cinsinden verilmiştir.

\subsection{3. Özgül Soğurma değerleri $\left(K_{232}, K_{270}\right)$;}

Kızartma yağlarının özgül soğurma değerleri AOCS Official Method Ch 5-91 metoduna göre saptanmıştır.

\subsubsection{Kızıl Ötesi Spektrumların Toplanmasl;}

Kızartma yağlarının kızılötesi spektrası 4000-650 cm-1 dalga boyu aralığında Fourier Dönüşümlü Kızılötesi Spektrometre (Bruker Tensor II) ile toplanmıştır (Bruker Inc., Billerica, MA,USA). Kızılötesi spektralar tek yansımalı ATR hücresi ile 4 $\mathrm{cm}^{-1}$ çözünürlükte ve $32 \mathrm{kez}$ taramalı olarak ölçülmüştür (Uncu ve Özen, 2019). Kızartma yağlarının kızıl ötesi spektraları iki tekrarlı olarak toplanmıştır.

\section{3. İstatistiksel Analizler}

Faktöriyel deneme deseninde belirtilen faktörlerin (yağ tipi ve kızartma tekrarı sayısı) kızartma yağlarının kimyasal özelliklerine olan etkisi varyans analizi (ANOVA) ile açıklanmıştır (MODDE 11, MKS Umetrics, Umea, Sweeden). Buna ek olarak kızartma yağlarındaki kimyasal değişimlerin daha iyi anlaşılabilmesi ve sınıflandırma yapılabilmesi için verilere Temel Bileşenler Analizi (PCA) uygulanmıştır (SIMCA 14.1, MKS Umetrics, Umea, Sweeden). 
Tablo 1. Derin Yağda Kızartma Isşlemi İ̧̧in Faktöriyel Deneme Deseni

\begin{tabular}{cccc}
\hline Deneme Sayısı & Örnek Kodları $^{*}$ & Yağ Tipi & Kuzartma Tekrarı $^{-}$ \\
\hline 1 & K3 & Kanola Yağ1 & 3 \\
2 & SY3 & Susuz Yağ & 3 \\
3 & K5 & Kanola Yağ1 & 5 \\
4 & SY5 & Susuz Yağ & 5 \\
5 & K7 & Kanola Yağ1 & 7 \\
6 & SY7 & Susuz Yağ & 7 \\
7 & K12 & Kanola Yağ1 & 12 \\
8 & SY12 & Susuz Yağ & 12 \\
9 & ON1 & Kanola Yağ1 & 5 \\
10 & ON2 & Kanola Yağ1 & 5 \\
11 & ON3 & Kanola Yağ1 & 5 \\
\hline *K= Kanola yağ1, *SY=susuz yağ, ON=orta nokta
\end{tabular}

\section{Araştırma Sonuçları ve Tartışma}

\section{1. \%Serbest Yağ Asitliği (\%SYA)}

Kızartma işlemi görmüş yağların \%SYA değerleri \% oleik asit cinsinden hesaplanarak, Tablo 2' de verilmiştir. Kızartma işleminde kullanılan kanola ve susuz bitkisel yağın başlangıç serbest yă asitlikleri sirasıyla $\% 0,76$ ve $\% 1,10$ olarak bulunmuştur. Kanola yağı ile yapılan kızartma işlemi tekrarınca serbest yağ asitliğinde bir miktar artış olduğu gözlemlenmiştir. Serbest yağ asitliğindeki benzer artış susuz yağ ile yapılan kızartma işlemlerinde de görülmüsşür (Tablo 2). Yağlarda serbest yağ asitliği değeri hidrolitik acılaşmanın yani, trigliseritlerin parçalandığının göstergesi olarak değerlendirilir. Donmuş patatesler, derin yağda kızartılırken ortama su bırakarak hidrolizasyon reaksiyonları başlatmışlardır (Gupta, 2005). Literatürde kızartma yağları için serbest yağ asitliğinin kabul edilebilir limitleri hakkında farklı görüşler bulunmaktadır. Yapılan bir çalışmada \%SYA'nın \%1'in üstüne çıkması halinde yağların kızartma işleminden çekilmesi (Tsang vd., 1996), başka bir araştırmada ise serbest yağ asitliği \% 4,95 değerine ulaşıncaya kadar (Melton vd., 1994) yağların kızartma işleminde kullanılabileceği savunulmaktadır. Amerika Ziraat Dairesi (USDA) tarafindan \%2 serbest yağ asitliği değeri limit olarak kabul edilmektedir (Sebastian vd., 2014). Genel olarak kizartma işleminde kullanılan her iki yağ tipinin \%SYA değerleri, 7. kez kızartma tekrarına kadar \%1'in altında kalmaktadır.

Serbest yağ asitliği için yapılan varyans analizi \%95 güven aralığında gerçekleştirilmiştir. ANOVA tablosunda görüldüğü üzere tüm faktörlerin ve interaksiyonlarının $p$ değerleri 0,05 'den büyük çıkmıştır (Tablo 3). Yani, kızartma işlemi için faktör olarak seçilen yağ tipi ve kızartma tekrarının, kızartma işlemi görmüş yağların serbest yağ asitliği içeriğine önemli bir etkisi olmadığı istatistiksel olarak belirlenmiştir.

\subsection{Peroksit Sayısı (PS)}

Kızartma yağlarının peroksit sayısı miliekivalen $\mathrm{O}_{2} / \mathrm{kg}$ yağ cinsinden hesaplanarak Tablo 2'de verilmiştir. Kızartma işleminde kullanılan kanola ve susuz bitkisel yağın başlangıç peroksit sayısı değerleri sirasıyla 5,77 ve $9,38 \mathrm{meq} \mathrm{O}_{2} / \mathrm{kg}$ yağ olarak bulunmuştur Kanola yağı ile yapılan kızartma işleminde, 3 kez kızartma sonrası PS'de hafif bir yükselme olurken, ilerleyen kızartma tekrarlarında ise PS'nin kanola yağının başlangıç değerine yakın bir değere düştüğü gözlemlenmiştir. Bu düşüş oluşan hidroperoksitlerin, diğer oksidasyon bileşiklerine dönüştüğünün göstergesidir. Kızartılmış kanola yağı örneklerinin PS değerleri, yemeklik yağlar için limit gösterilen değerin (10 miliekivalen $\mathrm{O}_{2} / \mathrm{kg}$ ) altındadır (Gunstone, 2009). Literatürde yapılan daha önceki çalışmalarda, farklı sürelerde kızartma işlemi görmüş kanola yağının peroksit değerlerinin daha düşük çıktığı görülmektedir (Aladedunye ve Przybylski, 2009; Farhoosh ve Kenari, 2009). Bitkisel susuz yă̆ örneklerinin peroksit sayısı değerleri limit değerin oldukça üzerinde çıkmıştır. Kızartma işleminin 7. tekrarında peroksit sayısında hafif bir azalma görülse de, genel olarak kızartma işlemi susuz yağın peroksit sayısı değerlerinde ciddi artışlara neden olmuştur (Gunstone, 2009). Peroksit sayısı açısından değerlendirme yapıldığında, bitkisel susuz yağın daha fazla okside olduğu ve derin yağda kızartma işlemine uygun olmadığı görülmektedir.

Peroksit sayısı analizi için yapılan varyans analizinde tüm faktörlerin ve interaksiyonlarının $\mathrm{p}$ değerleri 0,05 'den küçük çıkmıştır (Tablo 3). Yağ tipi ve kızartma tekrarının, kızartma yağlarının peroksit sayısı üzerine önemli bir etkisi olduğu istatistiksel olarak bulunmuştur.

\subsection{Konjuge Dien (K232) ve Trien (K270) Değerleri}

Yağlarda $\mathrm{K}_{232}$ değeri çoğunlukla çoklu doymamış yağ asitlerinden oluşan dienlerin miktarını gösterirken, $\mathrm{K}_{270}$ değeri ise yine çoklu doymamış yağ asitlerinin konjuge trienlere dönüşümü açıklar (Cağdaş ve Kumcuoğlu, 2015). Genel olarak, yağ tipinden bağımsız olarak kızartma tekrarı arttıkça, örneklerin $K_{232}$ ve $K_{270}$ değerleri artış göstermiştir. Yağlarda konjuge dien bileşiklerinin miktarının hidroperoksit oluşumuna paralel bir şekilde arttığı ve hidroperoksitlerin ikincil oksidasyon ürünlerine dönüşmesi sonucunda ise konjuge dien bileşiklerinin miktarının da azaldığı bilinmektedir (Dominguez vd., 2019). Kanola yağı ile 7 kez kızartma işlemi yapıldığında, peroksit sayısı ve konjuge dien değerlerinin birbirlerine paralel olarak artı̧̧ gösteriği tespit edilmiştir (Tablo 2). Rafine yağlar için $\mathrm{K}_{270}$ için limit değerleri ise 1.10-0.90 aralığındadır. Derin yağda kızartma işlemi kanola yağı kullanılarak yapıldığında, 5 kez kızartma işleminden sonra konjuge trien sayısının limit değerin üzerine çıkıldığı görülmektedir. Susuz yağ örneklerinin $\mathrm{K}_{232}$ ve $\mathrm{K}_{270}$ değerleri, limit değerin oldukça üzerindedir. $\mathrm{Bu}$ nedenle seçilen bitkisel susuz yağın $K_{232}$ ve $K_{270}$ değerleri açısından kızartma işlemine uygun olmadığı söylenebilir. Kızartma işlemi için faktör olarak 
seçilen yă̆ tipi ve kızartma tekrarının, kızartma işlemi görmüş yağların $K_{232}$ ve $K_{270}$ değerleri önemli bir etkisi olduğu istatistiksel olarak bulunmuştur $(\mathrm{p}<0,05)$. Kızartma yağlarının $\mathrm{K}_{232}$ ve $\mathrm{K}_{270}$ değerlerinin kızartma tekrarı arttıkça yükseldiği Şekil 1 'de verilen etki grafiğinde de açıkça görülmektedir.
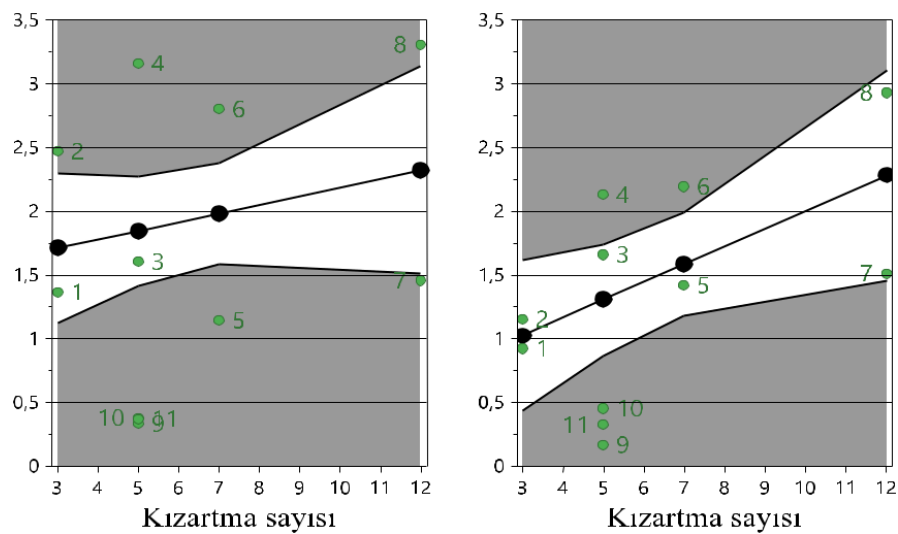

Şekil 1. Klzartma Tekrarının $K_{232}$ ve $K_{270}$ değerleri üzerine Etkisi

Tablo 2. Kızartma Yağlarının Kimyasal Analiz Sonuçları

\begin{tabular}{ccccc}
\hline $\begin{array}{c}\text { Yă } \\
\text { Örnekleri }\end{array}$ & \%SYA & $\begin{array}{c}\text { PS(meq } \\
\text { O2/kg yağ) }\end{array}$ & $\mathbf{K}_{\mathbf{2 3 2}}$ & $\mathbf{K}_{\mathbf{2 7 0}}$ \\
\hline $\mathbf{K 3}$ & 0,88 & 8,38 & 1,14 & 0,92 \\
$\mathbf{S Y 3}$ & 0,98 & 27,01 & 2,47 & 1,15 \\
$\mathbf{K 5}$ & 1,02 & 4,95 & 1,36 & 1,66 \\
$\mathbf{S Y 5}$ & 1,20 & 34 & 3,16 & 2,13 \\
$\mathbf{K} 7$ & 1,08 & 5,77 & 1,46 & 1,42 \\
$\mathbf{S Y 7}$ & 0,98 & 26,35 & 2,80 & 2,19 \\
$\mathbf{K 1 2}$ & 1,04 & 4,86 & 1,60 & 1,51 \\
$\mathbf{S Y 1 2}$ & 1,23 & 34,33 & 3,31 & 2,93 \\
$\mathbf{O N 1}$ & 1,28 & 1,45 & 1,33 & 1,17 \\
$\mathbf{O N 2}$ & 0,97 & 2,41 & 1,38 & 1,45 \\
$\mathbf{O N 3}$ & 1,04 & 1,44 & 1,37 & 1,32 \\
\hline Standart sapmalar $(\mathrm{SS}): \mathrm{SS}_{\mathrm{SYA}}=0,17, \mathrm{SS}_{\mathrm{PS}}=0,56, \mathrm{SS}_{\mathrm{K} 232}=0,03, \mathrm{SS}_{\mathrm{K} 270}=0,14$
\end{tabular}

Tablo 3. Kızartma Yağları Iç̧in ANOVA Tablosu

\begin{tabular}{lcccc}
\hline & \%SYA & PS & $\mathbf{K}_{232}$ & K270 \\
\hline Modelin p değerleri & 0,66 & $\mathbf{0 , 0 1}$ & $\mathbf{0 , 0 1}$ & $\mathbf{0 , 0 2}$ \\
Modelin uyum eksikliği & 0,57 & 0,08 & 0,75 & 0,88 \\
$\mathbf{R}^{2}$ & 0,19 & 0,96 & 0,85 & 0,73 \\
$\mathbf{R}_{\text {adj }}{ }^{2}$ & $-0,16$ & 0,94 & 0,78 & 0,62 \\
$\mathbf{Q}^{\mathbf{2}}$ & $-1,42$ & 0,88 & 0,66 & 0,49 \\
\hline Faktörlerin p değerleri & & & & \\
\hline Kizartma Tekrarı (KT) & 0,34 & 0,44 & 0,25 & $\mathbf{0 , 0 4}$ \\
Yağ Tipi (YT) & & & & \\
\hline Kanola Yağı & 0,54 & $\mathbf{0 , 0 1}$ & $\mathbf{0 , 0 2}$ & $\mathbf{0 , 0 1}$ \\
Bitkisel Susuz Yăg & 0,54 & $\mathbf{0 , 0 1}$ & $\mathbf{0 , 0 1}$ & $\mathbf{0 , 0 1}$ \\
\hline $\begin{array}{l}\text { İteraksiyonların p } \\
\text { değerleri }\end{array}$ & & & & \\
\hline YT(kanola)*KT & 0,64 & 0,43 & 0,93 & 0,52 \\
YT(susuz yag)*KT & 0,64 & 0,43 & 0,93 & 0,52 \\
\hline
\end{tabular}

\subsection{Kızılötesi Spektra Ölçümleri}

Infared spektra gibi spektroskobik analiz yöntemleri geleneksel yöntemlere alternatif olabilen, daha kısa sürede sonuç veren, örnek hazırlama aşamalarının çok daha kolay olduğu ve en önemlisi de örneklere zarar vermeden sonuç elde edilebilen yöntemlerdir (Gurdeniz vd., 2010). Kızartma işlemi görmüş yağların FTIR spektraları Şekil 2'de verilmiştir. Kızılötesi bölgede $1700 \mathrm{~cm}^{-1}$ dalga boyu civarında aldehitlerin ve sekonder oksidasyon ürünlerinin $\mathrm{C}=\mathrm{O}$ bantları absorbans vermiştir. $\mathrm{Bu}$ bölgede çoğunlukla $\mathrm{C}=\mathrm{O}$ bağları yani trigliseritlerin ester bağları gözlemlenmiştir. 2922 and $2852 \mathrm{~cm}^{-1}$ dalga boyu aralığında ise simetrik ya da asimetrik C-H bağları görülmektedir. 2950-2850 $\mathrm{cm}^{-1}$ dalga boyu aralığındaki değişimler genellikle $\mathrm{CH}_{2}$ bağlarındaki titreşimlerden kaynaklanmaktadır. Piklerin yoğun olarak görüldüğü bölge, parmak izi bölgesi olarak da adlandırılan $1250-700 \mathrm{~cm}^{-1}$ dalga boyu aralığıdır. Parmak izi bölgesinde, 1163 $\mathrm{cm}^{-1}$ civarlarında bulunan piklerin büyüklüğü ve yoğunluğu oksidasyon reaksiyonlarının gerçekleştiğini göstermektedir (Şekil 2). Kızartma yağlarının infrared spektraları önceki çalışmalarda bulunan sonuçlarla benzerlik göstermektedir (Du vd., 2012).

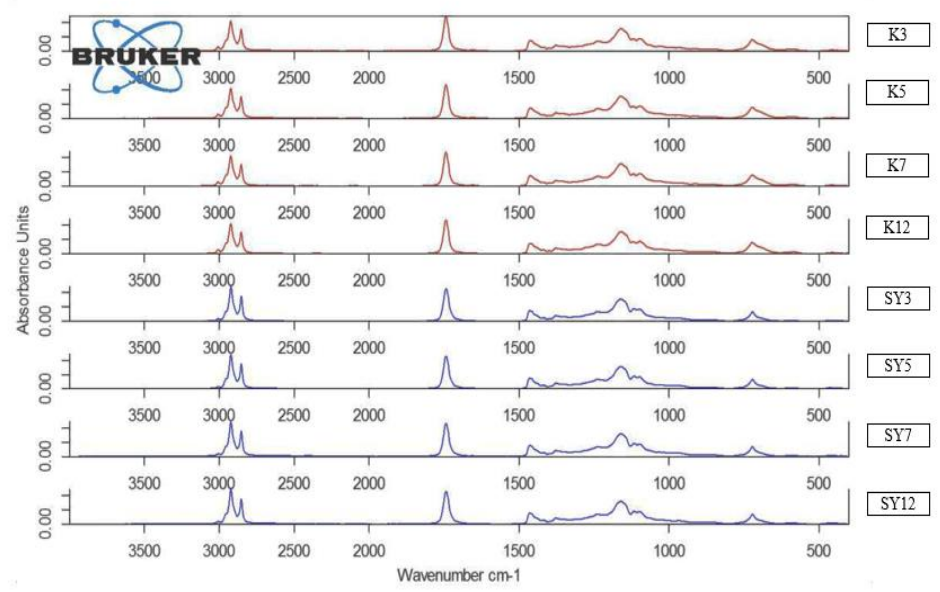

Şekil 2. Kızartma yağlarının Kızıl Ötesi Spektraları

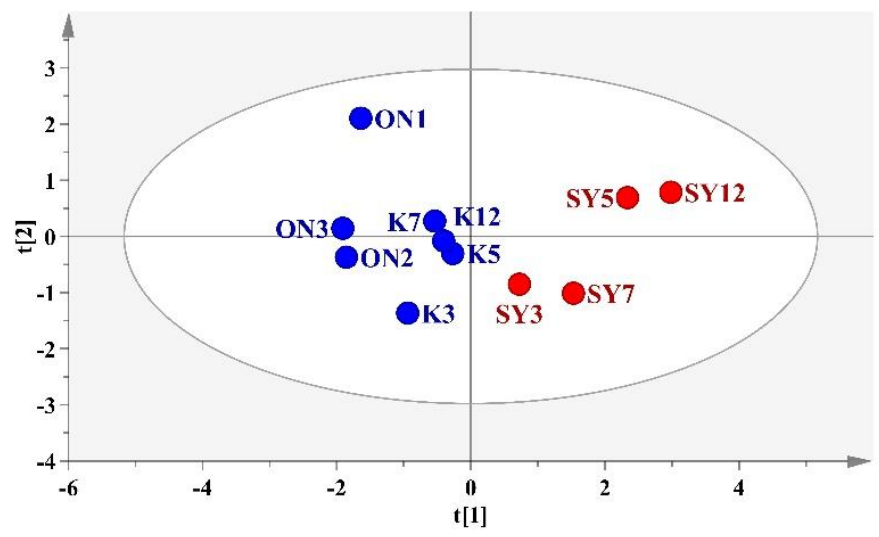

Şekil 3. Kızartma yağlarının kimyasal veriler kullanılarak oluşturulmuş dă̆llım grafiği

Derin yağda kızartma işleminde seçilen faktörlerin etkisini daha iyi analiz edebilmek adına verilere temel bileşenler analizi uygulanmıştır (Şekil 3). Serbest yağ asitliği, peroksit sayısı, $K_{232}$ ve $\mathrm{K}_{270}$ değerleri kullanılarak oluşturulan modelin içerdiği bileşen sayıs1 3 ve $\mathrm{R}^{2}=0,97$ olarak bulunmuştur. Şekil 3'de verilen dağılım grafiğinde görüldüğü üzere, kızartma yağları yağ tipine göre ayrılma göstermektedir. Mavi renkle belirtilen örnekler kanola yağını gösterirken, kırmızı ile boyanmış örnekler bitkisel 
susuz yağa aittir. Kanola yağı ile kızartılan örnekler elipsin sol tarafında kümelenirken, susuz yağ örnekleri elipsin sağ tarafına yerleşmiştir. Modele ait ağırlık düzlemi incelendiğinde ise, yağ tipine göre gerçekleşen bu ayrım çoğunlukla peroksit sayısı ile konjuge dien ve trien değerlerinden kaynaklandığ görülmüştür.

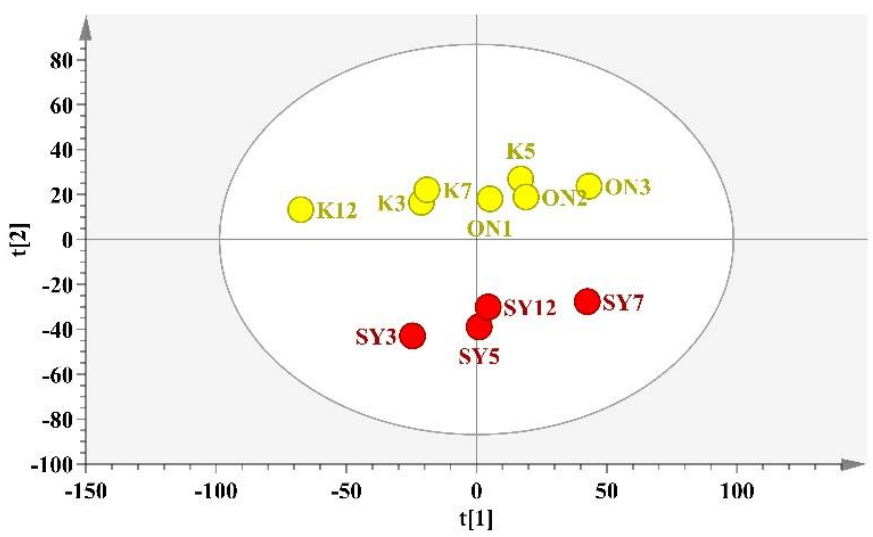

Şekil 4. Kızartma yağlarının kimyasal verileri ve kızılötesi spektra verileri kullanılarak oluşturulmuş dă̆llım grafiği

Derin yağda yapılan kızartma işleminin, yağların kimyasal yapısında yarattığı değişimlerin daha iyi açıklanması için temel bileşenler analizi tüm kimyasal verilerin ile kızılötesi spektra ile birleştirilmesiyle tekrarlanmıştır (Şekil 4). Oluşturulan yeni modelin içerdiği bileşen sayısı 5 ve $\mathrm{R}^{2}=0,95$ olarak bulunmuştur. Şekil 4'deki dağılım grafiği, kızartma yağlarının yine yă̆ tipine bağlı olarak sınıflandığını göstermektedir. Sarı renkle belirtilen örnekler kanola yağını, kırmızı olarak renklendirilen örnekler ise bitkisel susuz yağ örneklerini temsil etmektedir. Kanola yağ örnekleri elipsin üst çevresinde kümelenirken, kızarmış susuz bitkisel yağlar elipsin alt tarafına yerleşmiştir.

\section{Sonuç}

Derin yağda kızartma işleminde seçilen faktörlerin serbest yağ asitliği üzerine önemli bir etkisi olmadığı bulunmuş ve istatistiksel olarak açıklanmıştır. Yağ tipi ve kızartma tekrarının peroksit sayıs1, $\mathrm{K}_{232}$ ve $\mathrm{K}_{270}$ değerleri üzerine önemli bir etkisi olduğu istatistiksel olarak saptanmıştır. Kızartma tekrarı arttıkça, yağların peroksit sayısı, $\mathrm{K}_{232}$ ve $\mathrm{K}_{270}$ değerleri yükselmiştir. Susuz yağ örneklerinin peroksit sayısı, $K_{232}$ ve $K_{270}$ değerleri oldukça yüksektir. Oksidatif stabilite ve konjuge dien ve trien değerleri göz önünde bulundurulduğunda, belirtilen koşullarda derin yağda kızartma işleminde bitkisel susuz yağ ile yapılmamalıdır. 180 ${ }^{\circ} \mathrm{C}$ 'de derin yağda yapılacak kızartma işleminde kanola yağının kullanılması ve taze yağ eklemeksizin en fazla 7 kez kızartma işleminin tekrarlanması kızartma yağlarının kimyasal özellikleri açısından uygundur.

\section{Teşekkür}

Bu çalışma TÜBİTAK 2209/A Üniversite Öğrencileri Araştırma Projeleri kapsamında tamamlanmıştır. Bu projeye verdiklerı desteklerinden dolayı Türkiye Bilimsel ve Teknolojik Araştırma Kurumu'na teşekkürlerimizi sunarız. Ayrıca FTIR analizlerine yardımcı oldukları için Sivas Cumhuriyet Üniversitesi İleri Teknoloji Araştırma ve Uygulama Merkezi'ne de teşekkür ederiz.

\section{Kaynakça}

Ahmad, M. H., Shahbaz, Z., Imran, M., Khan, M. K., Muhammad, N., Iqbal, S., ... \& Ahmad, T. (2021). Monitoring of frying process in canola oil blend using fourier transform infrared and chemometrics techniques. Food Science \& Nutrition.

Aladedunye, F. A., \& Przybylski, R. (2009). Degradation and nutritional quality changes of oil during frying. Journal of the American Oil Chemists' Society, 86(2), 149-156.

AOCS. (1993). AOCS Official Method Cd 8-53. Official methods and recommended practices of the American oil chemists society method $C d$ 8-53. Peroxide value acetic acidchloroform method.

AOCS. (1997). AOCS official method Ca 5a-40. Official methods and recommended practices of the American oil chemists' society method $5 a-40$. Free fatty acids.

AOCS. (2005). AOCS official method Ch 5-91. Official methods and recommended practices of the American oil chemists society method Ch 5-91. Determination of spesific extinction of oils and fats.

Bou, R., Navas, J. A., Tres, A., Codony, R., \& Guardiola, F. (2012). Quality assessment of frying fats and fried snacks during continuous deep-fat frying at different large-scale producers. Food Control, 27(1), 254-267.

Cagdas, E., \& Kumcuoglu, S. (2015). Effect of grape seed powder on oxidative stability of precooked chicken nuggets during frozen storage. Journal of food science and technology, 52(5), 2918-2925.

Domínguez, R., Pateiro, M., Gagaoua, M., Barba, F. J., Zhang, W., \& Lorenzo, J. M. (2019). A comprehensive review on lipid oxidation in meat and meat products. Antioxidants, $8(10)$, 429.

Du, R., Lai, K., Xiao, Z., Shen, Y., Wang, X., \& Huang, Y. (2012). Evaluation of the Quality of Deep Frying Oils with Fourier Transform Near-infrared and Mid-infrared Spectroscop. Journal of food science, 77(2), C261-C266.

Fahri, Y., Onur, O., \& Ozge, O. (2015). Changes in quality characteristics of different deep frying fats during frying and regeneration potentials of different adsorbents in wasted frying oils. JFNR, 3(3), 176-181.

Farhoosh, R., \& Kenari, R. E. (2009). Anti-rancidity effects of sesame and rice bran oils on canola oil during deep frying. Journal of the American Oil Chemists' Society, 86(6), 539544.

Fujisaki, M., Endo, Y., \& Fujimoto, K. (2002). Retardation of volatile aldehyde formation in the exhaust of frying oil by heating under low oxygen atmospheres. Journal of the American Oil Chemists' Society, 79(9), 909-914.

Gunstone, F. (2009). Oils and fats in the food industry (Vol. 6). John Wiley \& Sons.

Gurdeniz, G., Ozen, B., \& Tokatli, F. (2010). Comparison of fatty acid profiles and mid-infrared spectral data for classification of olive oils. European journal of lipid science and technology, 112(2), 218-226.

Gupta, M. K. (2005). Frying of foods and snack food production. Bailey's Industrial Oil and Fat Products.

Melton, S. L., Jafar, S., Sykes, D., \& Trigiano, M. K. (1994). Review of stability measurements for frying oils and fried food flavor. Journal of the American Oil Chemists' Society, 71(12), 1301-1308.

Moreira, R. G. (2014). Vacuum frying versus conventional frying-An overview. European Journal of Lipid Science and Technology, 116(6), 723-734. 
Rababah, T. M., Feng, H., Yang, W., \& Yücel, S. (2012). Fortification of potato chips with natural plant extracts to enhance their sensory properties and storage stability. Journal of the American Oil Chemists' Society, 89(8), 1419-1425.

Saguy, I. S., \& Dana, D. (2003). Integrated approach to deep fat frying: engineering, nutrition, health and consumer aspects. Journal of food engineering, 56(2-3), 143-152.

Sebastian, A., Ghazani, S. M., \& Marangoni, A. G. (2014). Quality and safety of frying oils used in restaurants. Food Research International, 64, 420-423.

Sunisa, W., Worapong, U., Sunisa, S., Saowaluck, J., \& Saowakon, W. (2011). Quality changes of chicken frying oil as affected of frying conditions. International Food Research Journal, 18(2).

Tseng, Y. C., Moreira, R., \& Sun, X. (1996). Total frying-use time effects on soybean-oil deterioration and on tortilla chip quality. International journal of food science \& technology, 31(3), 287-294.

Tsuzuki, W., Matsuoka, A., \& Ushida, K. (2010). Formation of trans fatty acids in edible oils during the frying and heating process. Food Chemistry, 123(4), 976-982.

Uncu, O., Ozen, B., \& Tokatli, F. (2019). Use of FTIR and UVvisible spectroscopy in determination of chemical characteristics of olive oils. Talanta, 201, 65-73.

Warner, K. (2002). Chemistry of frying oils. In Food lipids (pp. 222-239). CRC Press.

Weisshaar, R. (2014). Quality control of used deep-frying oils. European Journal of Lipid Science and Technology, 116(6), 716-722. 